\title{
Data Logger Development to Evaluate Potential Area of Solar Energy
}

\author{
Asnal Effendi*, Arfita Yuana Dewi, Fauzan Ismail \\ Institut Teknologi Padang, Departement of Electrical Enginering, Padang, Indonesia
}

\begin{abstract}
The data logger was developed to evaluate potential area of solar panel. Current sensor and voltage sensor were integrated on data logger board to measure parameter that affected toward efficiency of PV system. The obtained Calculation power will be used for assessment and evaluation during collecting data. But, Maximum Power Point Tracking (MPPT) method will provide an efficient data of peak power. The benefit of using data logger is the ability to automatically collecting data on several period. The data can be plotted into V-I graph and P-V graph for analysis. The test bench result was recorded that the maximum power reaches $35 \mathrm{~W}$. This data logger with MPPT method can be used as portable recorder to compare the power in different area.
\end{abstract}

\section{Introduction}

Nowadays, solar energy contributed to support electric sources. It can reduce foreign energy dependence as well as energy-related environtmental impacts [1-2]. Another source like coal, hydro, nuclear, and gas are still used as a main source of energy. Solar radiation will be converted to sustainable-produced electricity by using photovoltaics (PV) technology. PV systems provided advantages to reduce gas emission was affected by green house, and reuse of marginal lands [2]. Installation of PV System utilize unused area, low productivity agricultural land, and special area such as roof top and wall. But, selected potential area to install PV System should be predicted to reach high efficiency.

Many literarures was introduced to predict solar power generation. Data mining method can be used to predict by recording interval, the number of training, and test datasets in review process. But, combination artificial neural network with data mining methods will provide an approach on predicted the area [3]. Fiftytwo method implemented for solar power prediction were explained and the performance was compared.

This prediction method is important to determine a prospect of PV System investment. Climate, position (latitude and longitude), solar angel, radiation, and result power, become some of parameters which should be consireded before selects the area. So, the benefit and advantage of PV system will be shown clearly. The results of prediction will be obtained by recording a parameter during one-year duration or more. Then assessment and evaluation toward recording data shows value of prediction.

Periodically parameter recording for every hour should be logged automatically during one-year testing. The hardware of datalogger consist of sensor, controller, and memory. Data logger should be designed simple, lowcost, fast response, and large space memory. Althought many perameter are sugested to be logged in this case. But, recording current and voltage become a simple way to see the power output performance of PV

\footnotetext{
* Corresponding author: asnal.effendi $@$ gmail.com
}

System that could give description about results of average power in a years [4].

This paper presented data logger development to evaluate potential area of solar energy. Current and voltage is measured and calculate to produces power output. The Atmega328 is acted as a controller that connected with RTC clock and Memory chip. Recording parameter for every hour and real time gives an important result to be assessted. Then, an implementation of Maximum Power Point Tracking (MPPT) method provides result of data recording [5].

\section{System Design}

The data logger was developed to measure voltage and current from solar panel. Microcontroller ATmega328 is used to measure data from sensor and arrange recording data from sensor to memory. Then, the RTC modul also use as a timer to recording data from solar panel. The block diagram of data logger shows part of modul board which connected to ATmega328 is displayed on figure.1. Real time measurement of current and voltage for every hour against solar panel with varies load. Where the electrical specification of Solar panel is explained on Tabel.1.

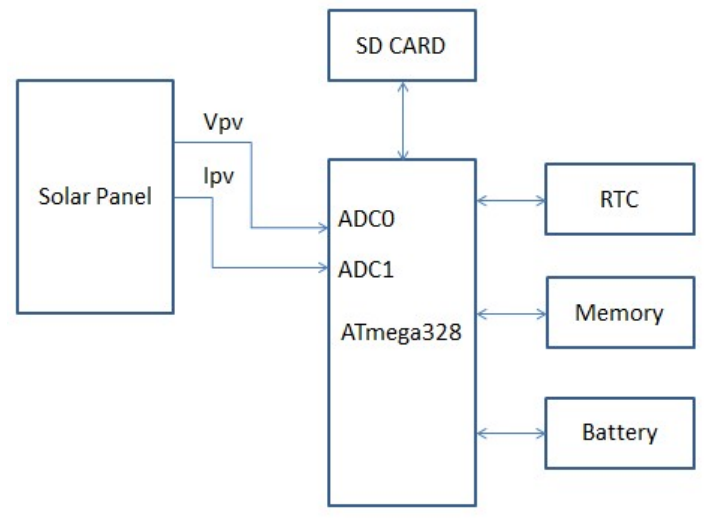

Fig.1. Block diagram of data logger system 
Table.1 Solar Cell Module Specification

\begin{tabular}{|l|l|}
\hline Modul Type & ASL-M50 \\
\hline Peak Power (Pmax) & $50 \mathrm{~W}$ \\
\hline Open Circuit Voltage (Voc) & 21 volt \\
\hline Short Circuit Current (Isc) & $1.45 \mathrm{~A}$ \\
\hline Voltage at Max Power (Vmp) & 16.8 volt \\
\hline Nominal Voltage & $12 \mathrm{~V}$ \\
\hline Tolerance & $5 \%$ \\
\hline
\end{tabular}

The latest data will be displayed on LCD Module with $2 \times 16$ character that connected to Atmega328. ACS712$20 \mathrm{~A}$ current sensor was measured real time current, and voltage divider circuit is used to sense the real time voltage from solar panel. Current, voltage and power calculation are saved in to memory internal of microcontroller. Then serial communication terminal can also be connected to computer to records all data saved on datalogger. As for component type of data logger module explained on Tabel.2.

Table.2. Component Specification of Data Logger System

\begin{tabular}{|l|l|}
\hline No & Components \\
\hline 1. & $2 \times 16$ LCD character \\
\hline 2. & Atmega328 \\
\hline 3. & SD Card Module \\
\hline 4. & RTC module \\
\hline 5. & 5V CMOS battery \\
\hline
\end{tabular}

An additional circuit is required for data retrieval. The test bench apply varies load during recording current, voltage, and power for every hour. Hence, the maximum power can be track by this method. Recording maximum power means the peak power can be accumulated to calculate cost and efficiency. The average value was produced by solar panel for every day becomes an important data to be saved. Where, the Maximum Power Point Tracking (MPPT) is a method to track a maximum power even though system on disturbance condition or variation on illumination.

Refer to figure. 2 that maximum power of solar panel is required to determine the potential area for solar system. When the PV systems suffer a low conversion efficiency, so MPPT be an answered to track the maximum value when the irradiant changed. The method was summarized by [Soulmia and Chenni,2016]. The thin film solar photovoltaics array was developed for building or unflat area with apply MPPT Method.

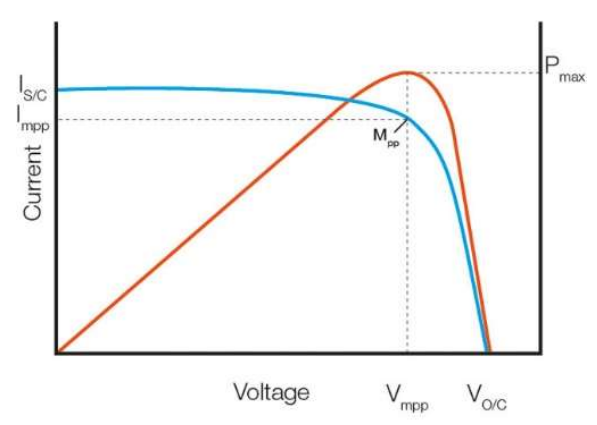

Fig.2. The normal I-V and P-V curve of solar panel.

\section{Prototype Development}

The data logger which integrated RTC circuit, curent and voltage sensor, 2x16 character LCD, SD Card Module to save data, and Atmega328 as a controller. This data logger board was install to $100 \mathrm{Wp}$ solar panel and connected to Solar Charging Circuit. Normally, this system will be charged battery and also loaded by steet light that displayed on Figure 3.

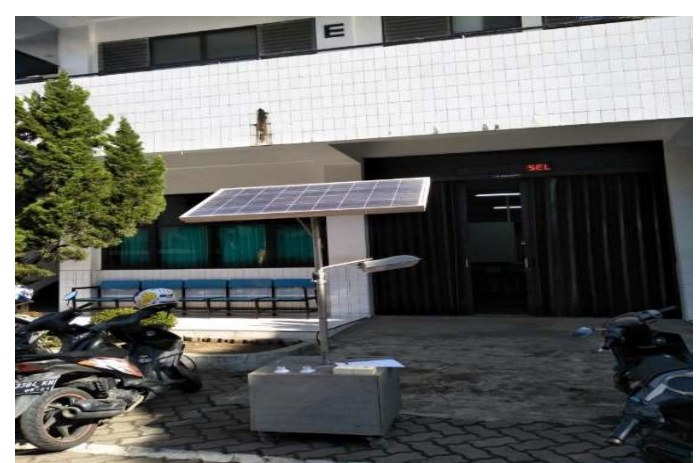

Fig. 3. Test Bench System of Photovoltaic

\section{Testing and Result}

The experiment has been done in front of Electrical Engineering Laboratory of Institut Technology Padang. The power measurement test was measured from 9 PM to 5PM with condition on sunny weather. The varies resistor was applied to search maximum power of solar panel.

Table.3 The first experiment on 15.00 PM

\begin{tabular}{|cccc|c|}
\hline No & $\mathbf{V}$ & $\mathbf{A}$ & $\mathbf{P}$ & $\mathbf{R}$ \\
\hline 1 & 1.692 & 1.496 & 2.531232 & $1 \Omega$ \\
\hline 2 & 3.773 & 1.496 & 5.644408 & $2.8 \Omega$ \\
\hline 3 & 11.142 & 1.489 & 16.590438 & $7.5 \Omega$ \\
\hline 4 & 17.236 & 1.473 & 25.388628 & $17.5 \Omega$ \\
\hline 5 & 18.116 & 0.669 & 12.119604 & $27.5 \Omega$ \\
\hline 6 & 18.662 & 0.441 & 8.229942 & $47.5 \Omega$ \\
\hline 7 & 19.102 & 0.217 & 4.145134 & $94.5 \Omega$ \\
\hline 8 & 19.246 & 0.142 & 2.732932 & $141.5 \Omega$ \\
\hline 9 & 19.307 & 0.105 & 2.027235 & $188.5 \Omega$ \\
\hline
\end{tabular}




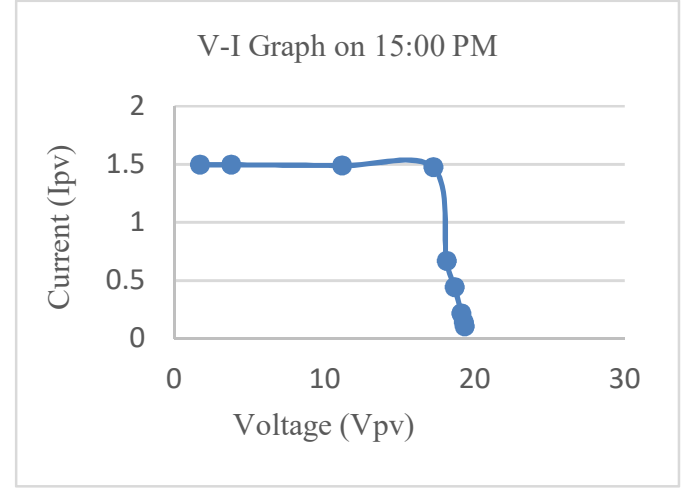

Fig. 4 The normal V-I Graph on experiment test 1

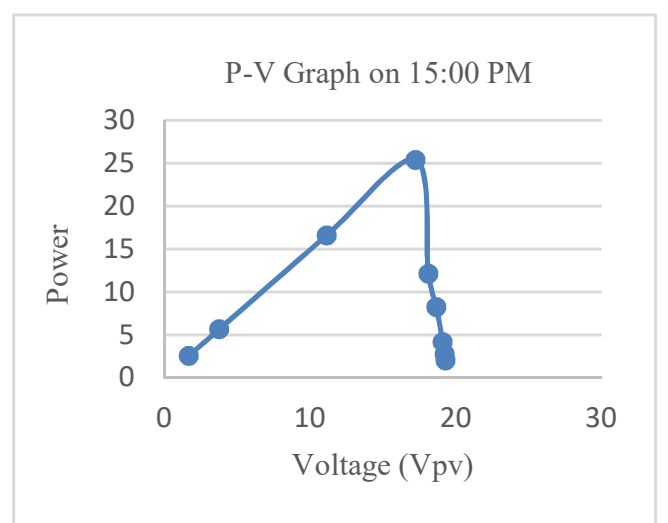

Fig. 5 The normal P-V Graph on experiment test 1

Table.4. The second experiment on 15.30 PM

\begin{tabular}{|ccc|cc|}
\hline No & $\mathbf{V}$ & $\mathbf{A}$ & $\mathbf{P}$ & $\mathbf{R}$ \\
\hline 1 & 2.92 & 2.818 & 8.22856 & $1 \Omega$ \\
\hline 2 & 7.8 & 2.728 & 21.2784 & $2.8 \Omega$ \\
\hline 3 & 16.43 & 2.133 & 35.04519 & $7.5 \Omega$ \\
\hline 4 & 18.52 & 1.063 & 19.68676 & $17.5 \Omega$ \\
\hline 5 & 19.04 & 0.7 & 13.328 & $27.5 \Omega$ \\
\hline 6 & 19.38 & 0.457 & 8.85666 & $42.5 \Omega$ \\
\hline 7 & 19.68 & 0.224 & 4.40832 & $82.5 \Omega$ \\
\hline 8 & 19.79 & 0.145 & 2.86955 & $136.5 \Omega$ \\
\hline 9 & 19.82 & 0.108 & 2.14056 & $183.5 \Omega$ \\
\hline
\end{tabular}

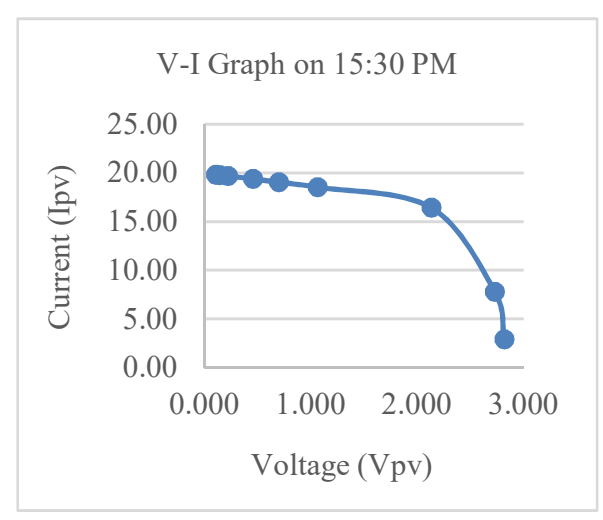

Fig..6. The normal V-I Graph on experiment test 2

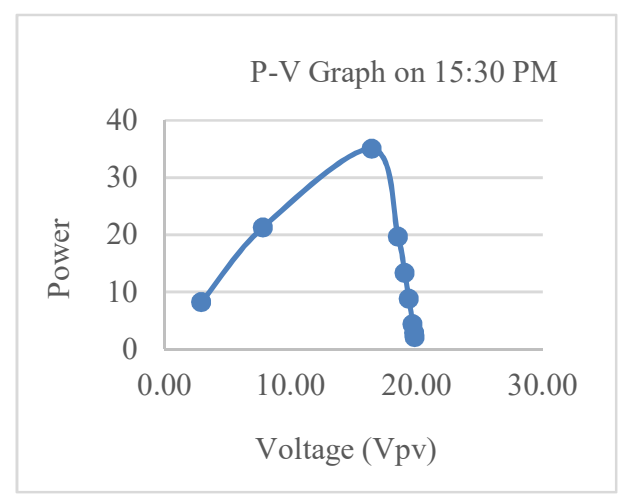

Fig.7. The normal P-V Graph on experiment test 2

Table.5 The third experiment on 16.00 PM

\begin{tabular}{|ccccc|}
\hline No & $\mathbf{V}$ & $\mathbf{A}$ & $\mathbf{P}$ & $\mathbf{R}$ \\
\hline 1 & 0.840 & 0.857 & 0.71988 & $1 \Omega$ \\
\hline 2 & 2.402 & 0.841 & 2.020082 & $2.8 \Omega$ \\
3 & 6.291 & 0.832 & 5.234112 & $7.5 \Omega$ \\
\hline 4 & 13.743 & 0.791 & 10.870713 & $17.5 \Omega$ \\
\hline 5 & 16.852 & 0.62 & 10.44824 & $27.5 \Omega$ \\
\hline 6 & 17.815 & 0.421 & 7.500115 & $42.5 \Omega$ \\
\hline 7 & 18.442 & 0.21 & 3.87282 & $82.5 \Omega$ \\
\hline 8 & 18.961 & 0.137 & 2.597657 & $136.5 \Omega$ \\
\hline 9 & 18.99 & 0.112 & 2.12688 & $183.5 \Omega$ \\
\hline
\end{tabular}

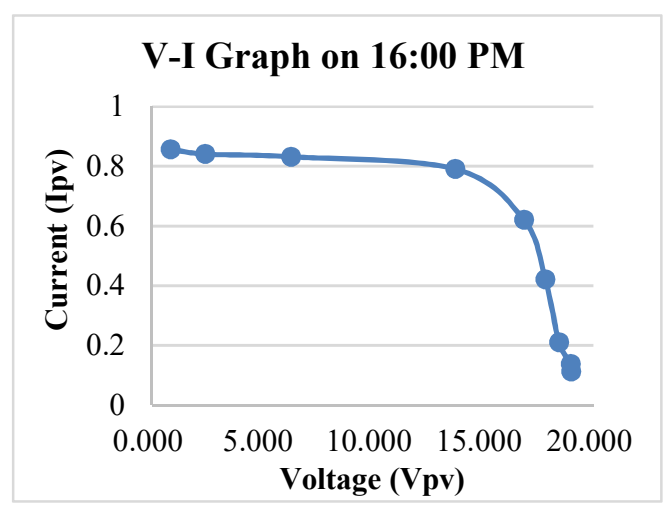

Fig.8. The normal V-I Graph on experiment test 3

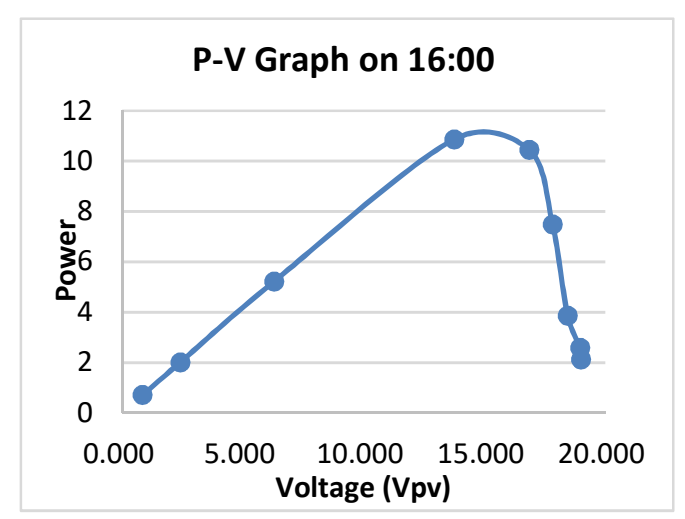

Fig.9 The normal P-V Graph on experiment test 3

Three experiment has been done to calculate maximum power of PV system for this place and condition. 
$35.045 \mathrm{~W}$ of maximum power measurement was produced by this PV sistem. The experiment that collected by data logger couldn't give a good performance yet. So, the experiment should be done for another predicted place then verify.

\section{Conclusions and recommendations}

The experiment for this place and condition couldn't give a good performance yet. Do another test for selected place for brief conclusion. The data logger successes collected current, voltage and power from pv system. Then, the data saved on SD card provides an important data collecting from PV system.

\section{References}

1. Panwar, N. L., Kaushik, S.C., Kothari, S., Role of renewable energy sources in environmental pro- tection: a review.' Renew.Sustain. EnergyRev.15, 1513-1524. (2011)

2. IPCC, 'Intergovernmental panel on climate change. IPCC Special report on renewable energy sources and climate change mitigation.' Summary for policy makers, Cambridge, United Kingdom and New York, USA. (2011)

3. Yesilbudak, M., Colak, M., Bayindir, R., A Review of Data mining and Solar Power Prediction.' International Conference on Renewable Energy Research and Application. 1117-1121. (2016)

4. Alami, M.E., Habibi.M., Bri, S., The Modeling of Maximum Power Point Tracking Controller for Increasing Efficiency of Solar Power System.' 3rd International Conference on Renewable and Sustainable Energy Conference (IRSEC). (2015)

5. Soualmia, A., Chenni, R., Survey of Maximum Peak Power Tracking Techniques used in Photovoltaic Power Systems.'Future Technologies Conference,430-443. (2016) 